\title{
Interface shear strength between slender bamboo rod and ruin soils with high plasticity
}

\author{
X.J. CHAI ${ }^{1}$, C.F.HE ${ }^{1}$ \& A.F. LI ${ }^{1}$,G.F. SIMA ${ }^{2}$ \& X.J. $\mathrm{LI}^{2}$ \\ ${ }^{1}$ Department of Civil Engineering, East China Institute of Technology, China \\ ${ }^{2}$ Graduate School of East China Institute of Technology, China
}

\begin{abstract}
KEYWORD: Ruin soils; slender bamboo rod; interface shear strength
\end{abstract}
ABSTRACT: For underground earthen sites in humid environment, its preservation is more difficult than the ones in northwest arid region. One reason is that the changing of existing environment, especially the changing of the groundwater resulting in the local cracks and creep-sliding disease of the underground earthen sites. In the study, according to the basic principles of protection and reinforcement of earthen site, the flexible bamboo rod was employed to intend to treat the creep-sliding disease of the underground earthen sites after excavation. The interfaces shear strength between slender bamboo rod and ruin soils were investigated by laboratory pullout tests and direct shear tests. The results will benefit for further study on the application of the slender bamboo rod for reinforcing the earthen sites in humid circumstances.

\section{INTRODUCTION}

Earthen site is an indispensable part of Chinese national culture heritage, which is famous for its long history and great value. In the Yellow river basin, the Yangtze River basin, a lot of earthen sites were retained, mostly for the ancient royal tomb, tombs, ancient early town sites and kilns etc. Due to the humid climate, rainfall and other factors, the earthen sites in humid circumstance are more difficult to reserve than the ones in arid region (Wang et al. 2013 \& Wang et al. 2008)

In the south of China, the precipitation of the Yangtze River basin is large and the air is humid. When the underground earthen sites were excavated, the following problems may occur due to the change of the existing environment: (1) the high groundwater level will made the ruins soils are in a saturated state with high creep properties; (2) a long period of heavy rainfall may lead to the collapse of the local instability of the pit wall; (3) the seasonal changing of the temperature and humidity of the climate may lead to cracking of ruins soils and accelerate the overall stability failure of the pit wall of the underground earthen sites (Zhou 2008, Zhou et al.2008)

For public exhibition purpose, a kind of chemical and physical method has been employed to preservation of the underground earthen sites after excavation ( $\mathrm{Su}$ et al. 2000, Li et al. 2010). Chai et al. $(2012,2013)$ made a series of laboratory test to verify the effectiveness of the chemical grouts (Methyl acrylic acid resin, silicon, PS solution) for preservation of Tianluoshan ruin soils, they included that none of the of them can match all the basic principles of the earthen sites preservation.

Wang et al. 2013 \& Li et al. 2010 developed a composite bamboo anchor and employed for reinforcing the earthen sites of Jiaohe ancient city, the practice indicated that the technique is effective for strengthening the large mass earthen sites in northwest arid region, yet the composite bamboo technique is not suitable for reinforcing the creep-sliding failure of the underground earthen sits in humid lowland region, this may be due to that the mechanism of creep-sliding failure in lowland humid region is different with that of earthen sites in drought climate.

In the study, according to the basic principles of protection and reinforcement of earthen site, the flexible bamboo rod was employed to intend to treat the creep-sliding disease of the underground earthen sites after excavation. The slender bamboo rod is inserted into the ruin soils which has creepsliding failure characters while excavation without boring and grouting process. Thus, the slender bamboo rod technique has the characters of pure physics, reversibility and compatibility of deformation, which can better match the basic principles of earthen sites preservation while treating the creep-sliding disease of the earthen sites in lowland humid circumstances. The interfaces shear strength between slender bamboo rod and ruin soils were investigated by laboratory pullout tests and direct shear tests. The results will benefit for further study on the application of slender bamboo rod for reinforcing the earthen sites in humid circumstances. 


\section{material properties}

\section{Relic soils}

Soils for laboratory tests were taken from the Tianluoshan earthen sites, Yuyao, Zhejiang province. The Atterberg limits of the relic soils are $\mathrm{w}_{\mathrm{p}}=20.0 \%$ and $\mathrm{w}_{\mathrm{L}}=40.2 \%$, which can be classified as silty clay (with high liquidity limit) (GB50007-2011). The soil passing $2.00 \mathrm{~mm}$ sieve was used for preparing soil specimen.

\section{Slender bamboo rod}

The dimensions of the slender bamboo rod are of diameter $4 \mathrm{~mm}$, the total length $340 \mathrm{~mm}$. The anchor length of the rod is set to be $100 \mathrm{~mm}, 150 \mathrm{~mm}, 200 \mathrm{~mm}$, and $250 \mathrm{~mm}$ respectively. Thus the slender bamboo rod has relatively low line stiffness and may deform coordinately with the creep-slide disease of the earthen sites.

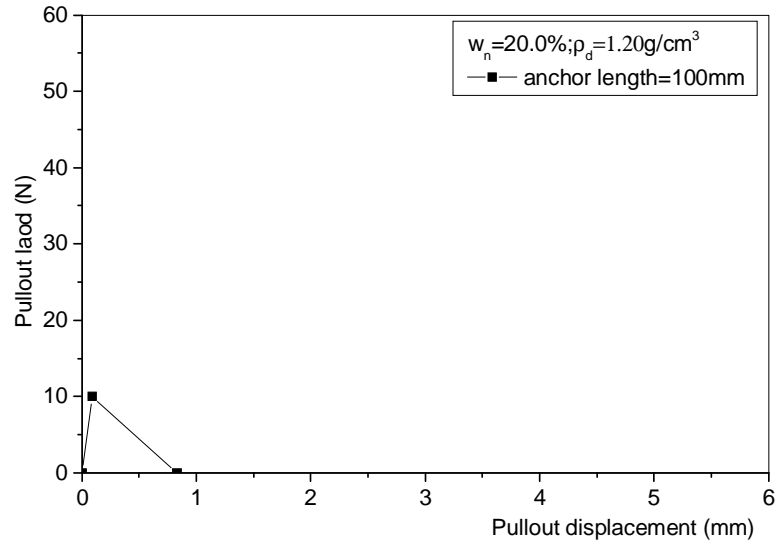

Figure 1 Pullout force vs. Displacement for case No.13 (anchor length $100 \mathrm{~mm}$ )

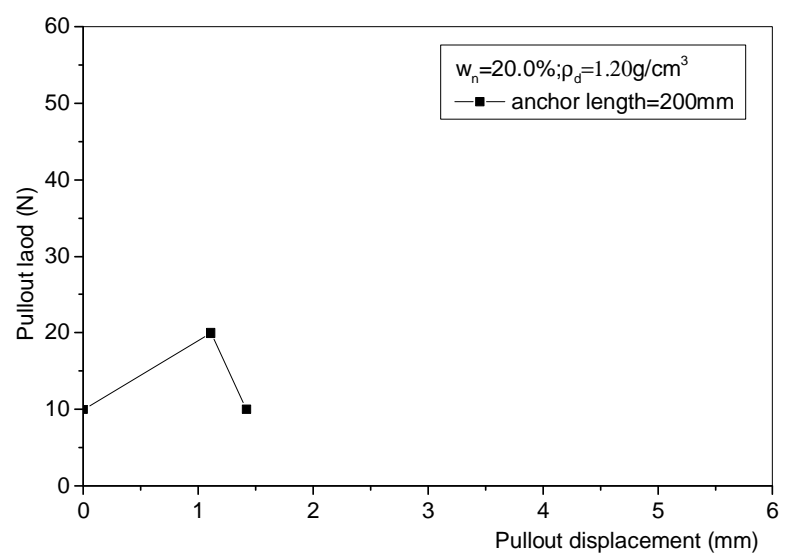

Figure 3 Pullout force vs. Displacement for case No.14 (anchor length $200 \mathrm{~mm}$ )

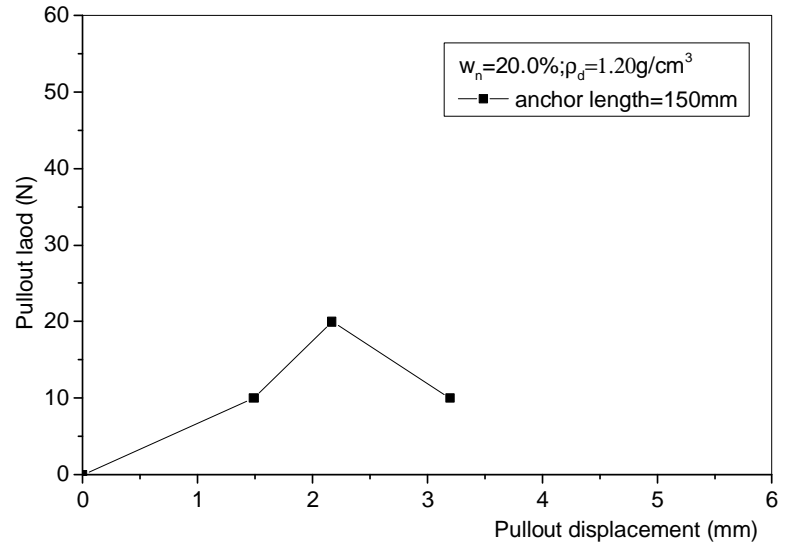

Figure 2 Pullout force vs. Displacement for case No.13 (anchor length $150 \mathrm{~mm}$ )

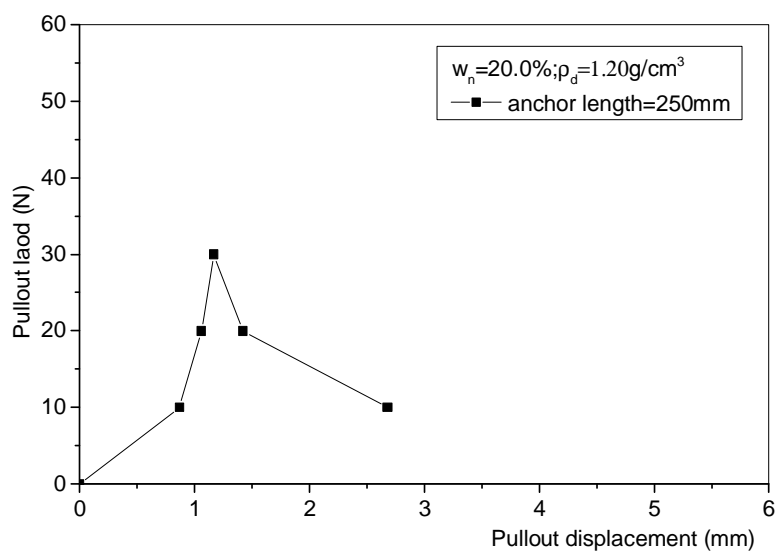

Figure 4 Pullout force vs. Displacement for case No.15 (anchor length $250 \mathrm{~mm}$ )

\section{test methodology}

\section{Soil specimen preparation for pullout test}

The dimension of soil specimen was set as cylinder with diameter $48 \mathrm{~mm}$ and height of $100 \mathrm{~mm}, 150$ $\mathrm{mm}, 200 \mathrm{~mm}$ and $250 \mathrm{~mm}$ respectively. The sample has prepared with dry density $1.20 \mathrm{~g} / \mathrm{cm}^{3}$ and water content $20.0 \%$. 
After molding of the soil samples, the slender bamboo rod was inserted directly into the soil sam ples by artificial static way. The test samples were sealed with plastic wrap and curing for 6 hours and then pullout tests were performed with pull speed $1.0 \mathrm{~mm} / \mathrm{min}$.

Table 1 List of pullout results for the four cases

\begin{tabular}{|c|c|c|c|c|c|c|c|c|}
\hline \multirow{2}{*}{$\begin{array}{l}\text { Case } \\
\text { No. }\end{array}$} & \multirow{2}{*}{$\begin{array}{l}\text { Water } \\
\text { content } \\
(\%)\end{array}$} & \multirow{2}{*}{$\begin{array}{c}\text { Dry densi- } \\
\text { ty } \\
\left(\mathrm{g} / \mathrm{cm}^{3}\right)\end{array}$} & \multirow{2}{*}{$\begin{array}{l}\text { Anchor } \\
\text { length } \\
(\mathrm{mm})\end{array}$} & \multirow{2}{*}{$\begin{array}{l}\text { Peak pullout } \\
\text { force } \\
(\mathrm{N})\end{array}$} & \multirow{2}{*}{$\begin{array}{c}\text { Interface } \\
\text { shear strength } \\
(\mathrm{kPa})\end{array}$} & \multirow{2}{*}{$\begin{array}{l}\text { Average } \\
\text { shear } \\
\text { strength } \\
(\mathrm{kPa})\end{array}$} & \multicolumn{2}{|c|}{ Ruin soils } \\
\hline & & & & & & & $\begin{array}{c}\text { Cohesion } \\
(\mathrm{kPa})\end{array}$ & $\begin{array}{l}\text { Friction } \\
\text { angle }\left({ }^{\mathrm{O}}\right)\end{array}$ \\
\hline 13 & 20 & 1.20 & 100 & 10.0 & 8.0 & \multirow{4}{*}{9.1} & \multirow{4}{*}{2.5} & \multirow{4}{*}{15.1} \\
\hline 14 & 20 & 1.20 & 150 & 20.0 & 10.6 & & & \\
\hline 15 & 20 & 1.20 & 200 & 20.0 & 8.0 & & & \\
\hline 16 & 20 & 1.20 & 250 & 30.0 & 9.6 & & & \\
\hline
\end{tabular}

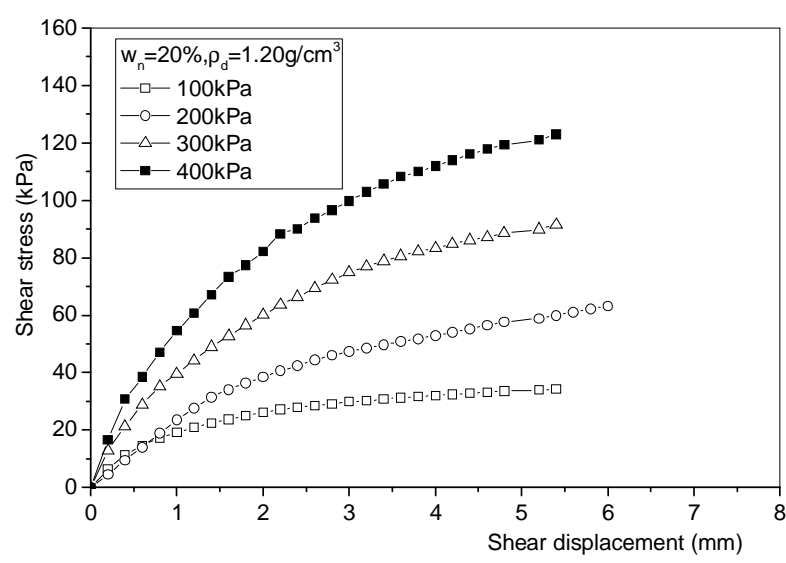

Figure 5 Shear stress vs. shear displacement for the test ruin soils (water content $20.0 \%$, dry density $1.20 \mathrm{~g} / \mathrm{cm}^{3}$ )

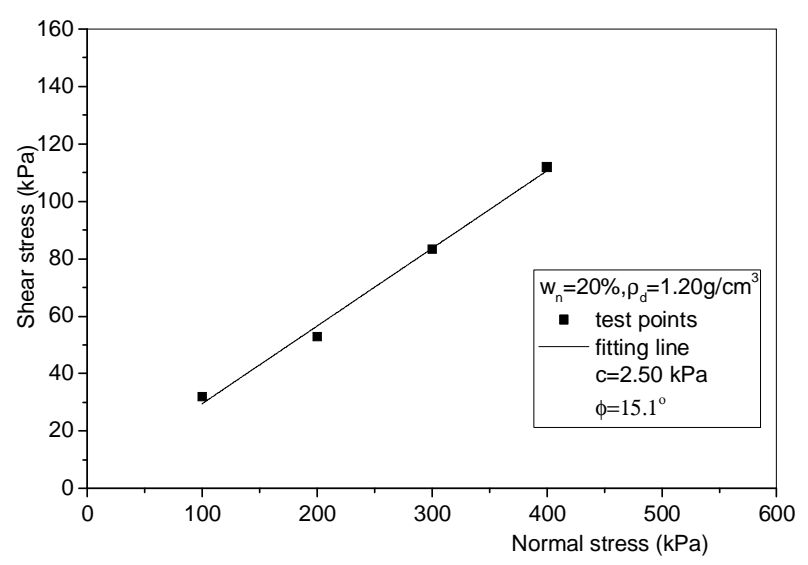

Figure 6 Peak shear stress vs. normal stress for the test ruin soils (water content $20.0 \%$, dry density $1.20 \mathrm{~g} / \mathrm{cm}^{3}$ )

\section{Direct shear tests}

To study the interface shear strength of the slender bamboo rod with the earthen soils, the shear strength parameters of the ruin soils were obtained by direct shear tests, the soil samples also has the same dry density $1.30 \mathrm{~g} / \mathrm{cm}^{3}$ and water content $20.0 \%$.

\section{Results and Discussion}

The pullout force vs. displacement relations for the four cases (No.13, No.14, No.15, No.16) are shown in Figure1-4.

Figure 1-4 show that the pullout peak forces occurred while pullout displacement about 0.5 $\mathrm{mm} 2.5 \mathrm{~mm}$, which are $10.0 \mathrm{~N}, 20.0 \mathrm{~N}, 20.0 \mathrm{~N}$ and $30.0 \mathrm{~N}$ for the corresponding anchor length 100 $\mathrm{mm}, 150 \mathrm{~mm}, 200 \mathrm{~mm}$ and $250 \mathrm{~mm}$ respectively. The peak pullout force increase with increase of anchor length.

The calculated shear strength of interface between slender bamboo rod with ruin soils are $8.0 \mathrm{kPa}$, $10.6 \mathrm{kPa}, 8.0 \mathrm{kPa}$ and $9.6 \mathrm{kPa}$ for the four test cases, as listed in Table 1. It reveals that the interface shear strength is consistent; the anchor length has little effect to the peak shear strength. The average interface shear strength is $9.1 \mathrm{kPa}$ for the four cases.

The direct shear stress with shear displacement relations for the ruin soils are plotted in Figure 5, it indicate that the shear stress increase with increasing of normal stress. The peak shear stress with the normal stress relation is shown in Figure 6, the linear fitting results give that the cohesion is 2.50 $\mathrm{kPa}$ and internal friction angle is $15.1^{\circ}$ for the test ruin soils. 
Comparing the cohesion of the ruin soils with the average interface shear strength, it revealed that the interface shear strength are composed of cohesion and internal friction angle with a corresponding interface normal pressure about $24.5 \mathrm{kPa}$.

\section{summary}

The conclusions can be drawn as follows:

1) The average interface shear strength between slender bamboo rod and ruin soils is $9.10 \mathrm{kPa}$ for the test ruin soil with water content $20.0 \%$ and dry density $1.20 \mathrm{~g} / \mathrm{cm}^{3}$, the anchor length has little effect to interface shear strength.

2) The average interface shear strength were composed of cohesion and internal friction angle with a corresponding interface normal pressure about $16.8 \mathrm{kPa}$ while ruin soil with water content $20.0 \%$ and dry density $1.20 \mathrm{~g} / \mathrm{cm}^{3}$.

3) The effect of anchor diameter, curing time, initial water content and dry density to the interface shear strength should be evaluated by further laboratory tests.,

\section{Acknowledgement}

The work described in this paper was supported by the National Natural Science Foundation of China (Grant No.51368002, Grant No.50968001), the Natural Science Foundation (20151BAB206056) ) of Jiangxi Provincial Department of Science and Technology, and the Science and technology support program (20151BBE50014) of Jiangxi Provincial Department of Science and Technology. The authors also thank the anonymous reviewers for their comments.

\section{References}

[1] Chai Xinjun, He Chunfeng, Yu Jiewen, Gao Yansheng, Rao Chenxi, 2012. Unconfined compression strength of Tianluoshan relic soils solidified by Methyl Acrylic Acid Resin. Advances in Industrial and Civil Engineering, Advanced Material Research, Vols.594-597, pp.343-346.

[2] Chai Xinjun, He Chunfeng, Gao Yansheng, 2013. Unconfined compresssion strength of Tianluoshan relic soils solidified by silicon, Advanced Materials Research, vols.610-613 , pp.29082911.

[3] Chen Peihang, Chai Xinjun*, Gao Jinhe, Wang Yujiao, 2013. Permeation Tests on Tianluoshan Relic Soils with Methyl Acrylic Acid Resin. Advanced Materials Research Vols.726-731,37063709.

[4] Li Zuixiong, Wang Xudong, Sun Manli, 2010. Research on consolidation techniques for conserving the ancient city of Jiaohe [M], Beijing, Science Press.

[5] Su Bomin, Li Zuixiong, Hu Zhide, 2000. Study on the mechanism of PS with earthen sites [J]. Duhuang Research, 2000(1):30-35(in chinese).

[6] Wang Xudong, Li Zuixiong, Chen Wenwu, Zhang Huyuan et. 2013. Research on key technologies of earthen sites preservation[M]. Beijing, Science Press.

[7] Wang xudong, Guo Qinglin, Zhang Huyuan, 2008. Weathering principle of and conservation treatment of the cliff at Mogao Grottoes, Proceedings of international symposium conservation of ancient sites 2008 \& ISRM-sponsored regional symposium, vol.2, 395-411.

[8] Zhang Changfa, Okada Ken, 2010. Earthen site protection training report [M]. Beijing, Cultural Relics Press.

[9] Zhou Huan, Zhang bing-jian, Chen Gangquan, Zhao Haiying, Zeng Yuyao, Guo Qinglin, Li Zuixiong, Wang Xudong, 2008. Study on consolidation and conservation of historical earthen sites in moisture circumstances conservation of Tangshan site in situ [J]. Rock and Soil Mechanics, . 29(4):954-962 (in chinese).

[10]Zhou Huan, 2008. Study on consolidation and conservation of earthen sites in moisture circumstances [D], Zhejiang University (in chinese) 